\title{
The sacralisation of popular culture as adolescent lived spirituality
}

\author{
Apostolides, Anastasia \\ University of South Africa \\ Soula.tea@gmail.com
}

\begin{abstract}
Many adolescents are drawn to the fantasy, science fiction and urban fantasy genres (movies and books), genres whose main characters include witches, wizards, vampires, ghosts, angels, demons, aliens and various other supernatural beings and events. Books and movies such as The Hobbit, Lord of the Rings (film series), Harry Potter (film series), $X$-Files, Twilight (film series), Star Wars (film series), and so on, are not only fervently consumed by some adolescents but have also, in some instances, been sacralised by adolescents (see Hopper 2005:116, McAvan 2012:5-10, Kirby 2013:2). In this article it will be argued that the reason for this, is that adolescents while questioning their identities and exploring their spiritualties, need a 'safe spiritual space' for this journey, one which may be related as something akin to what Berger termed the 'sacred canopy' where order can keep chaos at bay (Berger 1967: 51). This article will build on a lived theology perspective of how the divine can be experienced in the sources offered by popular culture texts that may become a 'sacred canopy' under which the adolescents can express their spiritual journeys.

This article hopes to contribute to the facilitation of more conversations taking place amongst parents, pastors and teachers on the importance of allowing adolescents more freedom in what movies and books they are allowed to see and read. These conversations may also be employed by pastors, parents and teachers as conversation openers with adolescents who are often reluctant to open up about topics that they find difficult to discuss. Osmer and Salazar-Newton (2014:70) encourage the church to 'think of ways it can take advantage of the interest of children and youth in fantasy literature,' on their spiritual life journeys.
\end{abstract}

\section{Spirituality and the sacred}

Spirituality is an ongoing life experience, and in this context it is defined as 'a craving deep within each human being for meaning' (Harris 2014:13). Sheldrake (2013:1) explains how the 'life project of spirituality' is 'oriented 
toward ultimate value, whether this is the Transcendent, the flourishing of humanity, or some other value.' Spirituality can be found within religious practices. For example, in Christianity: 'When the ultimate value is the triune God revealed in Jesus Christ and communicated through the Holy Spirit, and the project of self-transcendence is the living of the paschal mystery within the context of the church community, the spirituality is specifically Christian...' (Sheldrake 2013: 1).

Spirituality may also be found in everyday activities, such as reading, listening to music, gardening, watching movies, and so on, that may allow for a person to transcend and live out ultimate values within their everyday lives (on lived theology, see below) (Ganzevoort \& Roeland 2014: 95). All people are innately spiritual and continuously seek to understand the ultimate questions of Who? Why? and What? 'Spirituality, therefore, refers to the raison d'être of our existence, the meaning and values to which we ascribe' (Kourie 2015:2). Engaging with these ultimate questions may allow people to grow spiritually as they seek within their socio-cultural environment not only for the purpose and reason of their existence, but also seek to make a connection with the mysterious sacred. 'Spirituality seeks a sensitive, contemplative relationship with the sacred and is able to sustain levels of uncertainty in its quest because respect for mystery is paramount' (Tracey 2003: 11). Spirituality concerns itself with 'certain lifeenhancing beliefs about human dignity, human rights, and reverence for life' (Witmer \& Sweeney 1992:141).

Sheldrake (2013: 555) explains how 'the sacred' most often 'refers to a religious world view.' In Christianity 'the sacred' is related to God: 'God is revealed in and not simply by the person of Jesus of Nazareth at a particular time and place. Consequently, the foundations of a Christian understanding of the sacred are that God is manifested 'in the flesh' and in history' (Sheldrake 2013: 555).

For the purpose of this article the Christian understanding of spirituality and the sacred will be used. However, a more generic and secular understanding will also be taken into account as the postmodern genres addressed sometimes present their narratives from within a secular spirituality where the sacred can be glimpsed also from a Christian understanding. Du Toit (2006:1253) explains how secular spirituality is 
not confined to the religious, or transcendent sphere but characterises the profane, secular life world.' At other times, Christian spirituality is amalgamated with secular spirituality in the above genres, to create a mysterious element that is in a sense otherworldly.

\section{Changes of spirituality and the sacred at different stages of life}

As people get older, their spiritual needs and questions, and therefore there spiritual journey, will be different, namely as they evolve with the life experiences that confront them over a period of time. Hence a suitable quest and answer for a fifteen year old will be very different than for a thirty year old; likewise for a sixty year old person, and so on. This is why spirituality is not fixed: it changes with the person and is therefore a lifelong quest. Just as a person's spiritual life changes over the period of a lifetime, so too do the meaning of people's favourite novels and movies that they keep rereading and re-watching. With each re-reading of a novel or re-watching of a movie, a person brings implicitly to these stories their evolved self, so as to re-experience the story from another angle. Hence, the postmodern sacred texts that adolescents read as well as the movies they watch may be narratives that they return to at different stages of their later lives, in order to re-experience spiritual experiences from different points of view.

The search for spirituality is a personal endeavour, a choice to live out certain values that may lead to a path of growth and change. Kessler (1998:49) argues that in extreme situations, when adolescents do not have a 'genuine source of spiritual fulfilment', they turn to 'drugs, gang violence, and even suicide' as a way to escape from a meaningless existence. Hence, sources of meaning that allow people to ask the ultimate questions become a 'sacred canopy' (cf. Berger 1967), not only shielding the seeker from the chaos that may be going on around them, but also allowing alternative discourses to the chaotic ones of their 'realities'. Chaos in this article refers to the adolescent's social space that may include social dangers such as drugs, bullying and so on.

The above mentioned genres have, it should be noted, mystery at the core of their plots, and are 'sacred canopies' where the imagination may freely seek ultimate meaning which may allow for transcendence to be experienced 
within a safe space. For Ricoeur (1974:408), the imagination has the 'power of the possible', allowing for people to imagine the impossible. 'The imagination has a prospective and explorative function in regard to the inherent possibilities of man' (Ricoeur 1965:119). Hence, the imagination has the ability to allow a person to explore their innate potential. In a social context where a person feels suppressed, the imagination may be a way for them to realize aspects of their potential.

\section{The importance of the sacred canopy: Keeping order in a chaotic social context}

According to Berger (1967:51) it is religion / the sacred that supports social order. Religion / the sacred is 'confronted by man as an immensely powerful reality other than himself. Yet, this reality addresses itself to him and locates his life in an ultimately meaningful order' (Berger 1969:35). In a chaotic world, it is the sacred that 'domesticates' the dangers of constant chaos and 'its potency harnessed to the needs of everyday life' (Berger 1969:35). 'A sacred cosmos that will be capable of maintaining itself in the ever-present face of chaos' (Berger 1967:51); a 'sacred canopy' where hope and social order can be sought to keep chaos at bay. The 'sacred canopy', explains Berger (1973:36), provides a shield from the constant threat of chaos. In this context, Berger (1973:34) describes the sacred as 'a quality of mysterious and awesome power, other than man and yet related to him, which is believed to reside in certain objects of experience.' The sacred is a phenomenon that helps people give ultimate meaning to their existential daily problems. These are problems that people often have to face as a community and are, therefore, experienced by humanity as a whole (Berger 1967:37). In this way, people form social order, in what would otherwise be a chaotic and meaningless existence in people's social contexts. In this article, the sacred objects in question are the narratives (the books and movies mentioned) from postmodern genres where spirituality can be safely sought by people and used to make sense of their world. 


\section{Safe spiritual spaces: Living out and putting into action what is experienced in the fantasy, science fiction, and urban fantasy genres}

The above mentioned genres seem to appeal to adolescents as 'spiritual safe spaces', as some of these narratives contain spiritual and mysterious elements; so much so, that adolescents seem to have sacralised these genres, as these genres have become sources of spirituality for adolescents. Miller-McLemore ${ }^{1}$, argues that people often practically structure their lives by using Gospel values (Christian values), even though it may not be a conscious effort. Certain social actions have a 'theological conviction', founded 'on certain Scriptures'. Lived theology puts emphasis on putting into practice, on a daily basis, the beliefs that a person values, and may then utilize these personal values in the everydayness of their lives. Ganzevoort and Roeland (2014:95) investigate phenomena such as gardening, fantasy, movies and so on, to understand how people utilize popular culture and daily activities in their everyday lives to experience sacredness and transcendence. Ganzevoort \& Roeland (2014:95) explain that activities such as gardening 'are far from trivial': such practices are 'highly meaningful ways of being'. Activities such as those mentioned above may well contain sacred elements. Hence, the 'practical' in practical theology has moved from the church to the social. 'For practical theologians working in a pluralized, secularized, and deinstitutionalized context, praxes such as gardening provide meaningful access to hidden or implicit spiritual lives of people today' (Ganzevoort \& Roeland 2014:100).

The 'safe spiritual spaces' created by popular culture are crucial to the adolescent spiritual journey, helping adolescents contextualise their spiritual journey, even when they claim to be rejecting anything to do with 'God' and religion (see Apostolides 2016:1-5). Milbank (2005:31) argues that to revive belief in a triune God and to re-enchant people with the created mysteries, 'the new tellers of fairy-tales to children and adults open out just this real horizon.' Adolescents are replacing one source of spirituality,

\footnotetext{
1 http://www.faithandleadership.com/qa/bonnie-j-miller-mclemore-theology-religious-communities-andpractice

2 http://www.faithandleadership.com/qa/bonnie-j-miller-mclemore-theology-religious-communities-andpractice
} 
for example religion / God / a supernatural being, with alternative ways to express spirituality within their daily lives. Adolescents are looking at trendier versions of spiritual sources, or as Schofield Clark (2002:795) states this, the 'funky' side of religion (referring to X-Files, The Craft and so on), that defy conventional spiritual sources (for example institutionalised religion) of adolescent's parents. Adolescents often reject their parents' values at this stage of their lives, becoming moody and difficult to talk to, clashing with what they may have previously valued (see Fowler 1981:182, Coles 1998:143). This may be an awkward stage for the adolescent, with physical and emotional changes happening at a rapid pace (Coles 1998:135). Suffice it to say, the adolescent phase in the human being's life cycle can be a particularly trying one. Problems such as drug abuse, materialism and spiritual emptiness are of course not new problems for the adolescent, but have risen steeply of late (Whitman and Chetwynd 1997:24).

People prefer to relate to people who are similar to themselves, as this maximizes their own identity (Lum 1982:386). Hence, adolescents may use the above genres to search for identity and spirituality as their friends are talking about them, making them popular choices. Adolescents may use also these alternative spiritual sources (above mentioned genres), to understand and fit into their place within their own youth social-cultural space. Activities (such as watching movies and reading books from these popular culture genres) seem to address the void that the traditional systems (e.g. the church) have left open, and with which adolescents have become disenchanted (Beaudoin 1998:21). These activities and how they are expressed by adolescents may even be recognised as the 'new' symbols of society (Beaudoin 1998:21). These genres may also serve as important sources of spirituality for adolescents who have few ties with formal religion (Schofield Clark 2002:794). McAvan (2012:5-10) has coined the phrase 'postmodern sacred' to describe popular cultural spirituality that has been sacralised and is used by people to shape and live out their spiritualties (MacAvan 2012:7).

Often adolescents claim not to be religious, although they may still express spirituality enabled by the various forms of popular culture (spiritual sources) they are exposed to (Beaudoin 1998:34). McAvan (2012:8) notes that, while 'New Age ideas of the spirit' are influential to the 'postmodern sacred', 'it is also important to note that the figure of God has not been 
completely abandoned', along with symbols of the cross and 'Christian tropes of redemption and sacrifice'. Therefore, these 'postmodern sacred' discourses may inspire adolescents to transform their spiritual identities without their knowledge of where these spiritual sources originate. The story of Christ (compassion, love of community and sacrifice to protect that community) is closely woven into the fabric of mundane stories of people's socio-cultural environment, as are Christian symbols. Hence, the story of Christ is often expressed in the creative stories of the 'postmodern sacred'. Two such fantasies are Lord of the Rings film series and the Harry Potter film series, where the story of Christ can be glimpsed by the reader (see Apostolides \& Meylahn 2014:1-6). Consequently, even though some adolescents claim not to be religious, they still express spirituality by using their social context (Christ discourse) to transform and shape their spiritual identities on a daily basis (lived theology).

As was mentioned above, one such literary and visual phenomenon is the Harry Potter film series, with the Christ discourse woven into the story, which has become lived theology for children and adults alike (see Apostolides \& Meylahn 2014:1-6). The series was completed nearly a decade ago, and the then adolescents who read the books are now adults. This means that the series have become part of the lived experiences of these adults' everyday lives, influencing how they act towards their fellow human beings. Therefore, the Christ discourse that they experienced in the series may have transformed their actions to mimic those of Christ's actions - actions such as love, fellowship and compassion.

JK Rowling, author of the Harry Potter film series, was not intent on converting anyone to Christianity; she simply drew on her own religion within her own social context: 'That's an allusion to a belief system in which I was raised.' Having lost her mother to multiple sclerosis when Rowling was twenty-one, she grappled with depression. Rowling has explained that the series would not have had the topics of love, death and motherhood at its core, had it not been for losing her mother. Rowling used the story to explore topics such as: Does someone stop loving you because they died? What is beyond death?, and so on. In other words, Rowling used the sacred

3 http://www.harrypotterspage.com/2010/10/03/transcript-of-oprah-interview-with-j-k-rowling/ 
story of Christ (love, sacrifice, resurrection and fellowship) to explore her depression and what it means to be a mother (which she herself is), as this was the story that was part of her spiritual journey and of her socio-cultural upbringing.

\section{The sacralisation of the postmodern sacred: The adolescent spiritual journeys}

Sheldrake (2013:409) explains how 'literature in general speaks of the human condition and therefore touches on a spiritual dimension but in a more specific way there are works which deliberately embrace an understanding of spirituality and use it as a creative principle.' Narratives explore how people experience their lives over a period of time. All stories (both factual and fictional) take place within a specific social context and take place over a certain period of time (this could be a few hours, days, months, years or decades). All stories follow the sequence of beginning, middle and end, with certain actions and consequences occurring within the period of time. Taylor (2002:420) explains that while the end of the story means that there is no more to read, it also means that something has been accomplished or experienced by the main character/ characters. 'The end is the final working out of all the latent potential of the beginning, and the consequences of the choices in the middle' (Taylor 2002:420). This means that the end of the story shows the worth of characters choices. These choices have sometimes allowed the main characters to transform, and the reader may find that they too have had some kind of transformation. Such a transformation may lead to a transcendental experience for the reader.

Stories such as those offered by the postmodern sacred are stories with the 'spiritual as a creative principle' (McAvan 2012:6). Postmodern sacred narratives 'consist of texts that are consumed in part for their spiritual content, for an experience of the transcendent ambivalent situated in the boundary of formal religious and spiritual traditions' (McAvan 2012:6). Adolescents have sacralised these stories in that they recognize the sacred qualities contained in these texts. Certain stories help people by providing answers, even if they are not always suitable to answer fully the ultimate questions mentioned in the opening paragraphs. Here, Crites's (1971:294297) understanding of sacred and mundane stories will be applied to 
postmodern sacred texts, as Crites understanding of narrative within storytelling captures the essence of stories that reveal the sacred. Sacred and mundane stories are those that provide people with a sense of purpose, a meaning to their lives and the antithesis of a meaningless existence. In other words, these are the stories that put social order in an otherwise chaotic society; stories that in a broader sense keep hope alive. People construct and express the meaning of their lives through these stories. Sacred stories are stories that are interlaced into the fabric of our socio-cultural context. Sacred stories 'inform people's sense of the story of which their lives are a part, of the moving course of their own action and experience' (Crites 1971:295). Mundane stories are the stories that people hear or see directly (Crites 1971:295). Mundane stories require a plot and 'narrative devices', as they are stories of the everyday experiences of a particular world. 'In order to tell a story it must be set within a world' (Crites 1971:296). It need not be a real world, but even a fictional story requires a world. According to Crites (1971:296) 'even the scriptures, are mundane stories. But in these, as well as in some works of literary art, and perhaps even in some merry little tales that seem quite content to play on the surface, the sacred stories resonate.' Therefore, in fictional stories (particularly postmodern sacred stories) the sacred of the story is what gives the story its mysterious element, leading the reader to seek spiritual answers, while the mundane part of the story is the everyday setting that the reader or moviegoer can connect with to start her/his spiritual journey. 'The sacred resonates' from the mundane, and 'people are able to feel this resonance, because the unutterable stories are those they know best of all' (Crites 1971:297). This means that the concealed sacred story within the mundane story is recognized by people as their socio-cultural world view that gives ultimate meaning to life. Sacred stories are therefore essential to a person's spiritual journey of transformation as they 'break the story to tell a truer story!' (Crites 1971:297).

The postmodern sacred are mundane stories where sacred stories can be glimpsed safely in the 'sacred canopy' of the imagination. Wilhelm and Smith (Wilhelm 2016:37-41) did a three-year study, engaging adolescents on the books they choose to read. This often means that these are the books that are marginalized at schools and sometimes by parents too. Usually this is because these books contain witchcraft and occultism in various forms. Hence, adult's censor the reading of these books as they are worried 
that adolescents will be persuaded by these books to have an unnatural fascination with witchcraft and occultism. J.K. Rowling therefore spoke to Oprah Winfrey about being accused of using witchcraft and dark magic in the Harry Potter film series. In this interview, Rowling explains how people look to religion as outside support, support outside of themselves. 'So, in religion, of course, you're looking for outside support but that's the appeal of magic. I'm not saying I believe magic is real. I don't. But that's the perennial appeal of magic - which we ourselves have power and we can shape our world.' ${ }^{4}$ Therefore, the magic in such novels is that we can choose to shape our lives in an alternative manner to the chaos going on in our 'reality'. Therefore adolescents have the power to change their 'realities' and not fall into group cultural traps such as drugs for example.

However, what was found by Wilhelm and Smith (Wilhelm 2016:37-41) in the above study was that adolescents were not becoming obsessed with witchcraft and occultism from reading these books.

'In other words, kids don't consume books like junk food - they transact with them and make them their own. ...readers are not operated by the books, but they operate on the books. Readers actively make meanings - they don't passively receive them and the meanings they make are relevant to their current lived experience and life challenges' (Wilhelm 2016:37).

People actively partake in the stories that they are reading by placing themselves in the characters' world. The reader takes a journey of the imagination in which s/he interacts with the text, to create an alternative world. Therefore the reader is shown alternative understandings of certain discourses and has the opportunity to project her/his own potential onto this created world. People read and likewise watch movies 'either in order to realise ourselves or in order to forget ourselves' (Jenkinson 1946:153). However, by forgetting ourselves we may be able to make better contact with ourselves and our place in our social reality. Zipes (2008:6) explains that the fantastic helps the reader to 'reflect seriously and imaginatively about the customary ways she/he engages with the world... Hope for change can only be created if the fantastic illuminates and exposes delusion.' Tolkien

4 http://www.harrypotterspage.com/2010/10/03/transcript-of-oprah-interview-with-j-k-rowling/ 
(2008:64) also argues that a good fantasy does not want to delude the reader, but wants to enrich the reader. A good fantasy wants to expose the reader to their corrupt 'reality', helping the reader to 'survive' in their 'real' world (Tolkien 1964:35). Postmodern sacred environments address the chaos of the 'real' world, but without the adolescent having to be 'really' engaged in the chaos.

Osmer and Salazar-Newton (2014:51-71) conducted a project called Growing Up with Harry Potter, during which 93 interviews were conducted with as many young adults who had grown up reading the Harry Potter novels. The research found that 'readers easily identified a number of moral themes like death, love, choice, friendship, sacrifice, prejudice/intolerance, the ambiguity of evil/good, family and mother love' (Osmer \& SalazarNewton 2014:69). However, it was also found that some readers had not reflected on the above themes (Osmer \& Salazar-Newton 2014:69). It appears that while many readers had discussed some aspects of the novels with family and friends, they had never had the opportunity to explore these themes in a more significant way in more formal set-ups (school, church or even a book group). For most of the participants involved in this project, this had been the first chance they had had to contemplate the above mentioned themes. The participants expressed that they now wanted to re-read these novels and re-think the questions that were posed to them in the project. Osmer and Salazar-Newton explain how this reveals 'a readiness and eagerness for this kind of discussion' (Osmer \& SalazarNewton 2014:69). 'It also was striking to note the thoughtfulness of the few readers who now were married and had children. They displayed more self-awareness of what the books added to their life, especially their understanding of virtues and vices and the moral grey area in some of their choices' (Osmer \& Salazar-Newton 2014:70). Therefore, adolescents may be wanting to discuss the themes that postmodern sacred stories offer, but may not know how to open such a conversation, as these books and movies are marginalized by at least some of the people with whom they would want to discuss these themes. Hence, if given a chance, not only do the postmodern sacred texts offer a way for parents, teachers and pastors to open conversations with adolescents, but they also offer room for the adolescent to initiate such conversations, which may further their spiritual transformation: 'Popular culture directly enables religious participation, 
transformation, understanding and experience' (Partridge 2004:141). Hence, postmodern sacred texts have long lasting effects on the adolescent who will carry these values into adulthood. These values may then form a strong foundation for the ongoing life project of people's lived experiences.

\section{Concluding thoughts}

Postmodern sacred narratives provide a kind of sacred canopy (cf. Berger 1967) in which adolescents can safely question, seek and discover their spiritualties. Adolescents identify with the mysterious elements of the story, using these elements to form personal values and then live these values out in 'reality', in their ongoing spiritual journeys. These stories often fill the gap that institutionalized religion has left for some adolescents. Adolescents have sacralised these texts and use aspects of these stories that pertain to their lives and integrate facets of these stories into their spiritual lives. The chaos that sometimes occurs in adolescents 'realities' can be put into context and an alternative spirituality can be chosen. These texts may give adolescents the courage to make things better for themselves.

Being an adolescent can be a frustrating time in a person's life. Adolescents may be too embarrassed to share a particular problem as they maybe worried that they may be misunderstood, making it hard for them to reach out to another person. Therefore, these texts are valuable tools of communication for parents, pastors and teachers. Their value is underestimated and too often marginalized by adults who fear the witchcraft element in the texts. However, these texts may be a means of opening up meaningful conversations about difficult topics. These texts are also a means for adolescents to experience the sacred and transcendence from within their own cultural understanding. As pointed out by Ganzevoort and Roeland (2014:100), activities from popular culture become gateways for practical theologians to understanding people's unspoken spiritual lives.

\section{Bibliography}

Apostolides, A 2016. South African fantasy: Identity and spirituality. In HTS (Teologiese Studies/ Theological Studies) 72 (1), http://dx.doi. org/10.4102/hts.v72i3.3255 
Apostolides, A \& Meylahn, J-A 2014. The lived theology of the Harry Potter series. In HTS (Teologiese Studies/ Theological Studies) 70(1), $1-6$.

Berger, PL 1969. The sacred canopy: Elements of a sociological theory of religion. New York: Anchor Books

Berger, PL 1973. The social reality of religion. Norwich: Penguin University Books.

Beaudoin, T 1998. Virtual faith: The irreverent spiritual quest of Generation X. San Francisco: Jossey-Bass.

Coles, R 1998. The moral intelligence of children: How to raise a moral child. New York: Plume.

Crites, S 1971. The narrative quality of experience. In Journal of the American Academy of Religion Vol 39, No 3, 291-311.

Du Toit, CW 2006. Secular spirituality versus secular dualism: Towards post secular holism as model for a natural theology. In HTS (Teologiese Studies/ Theological Studies) 62 (4), 1252-1268.

Fowler, JW 1981. Stages of faith. San Francisco: Harper \& Row.

Ganzevoort, RR \& Roeland, J 2014. Lived religion: the praxis Practical Theology. In IJPT 18 (1), 91-101.

Harris, KI 2014. Embracing make believe play and theories of childhood: Understanding children's spirituality and the spiritual essence of a young child. In International Journal of Integrative Pediatrics and Environmental Medicine, 12-21

Hanegraaff, W 2000. New age religion and secularization. Numen 47 (3), 288-312: New York.

Heimbrock, HG 2010. Beyond secularization: experiences of the sacred in childhood and adolescence as a challenge for RE development theory'. British Journal of Education. [Online]. Available: http:/www.tandonline. com/loi/cbre20 on 27 [Accessed: November 2013]

Hopper, R 2005. What are teenagers reading? Adolescent fiction reading habits and readingchoices. Literacy, 113-120. 
Hyde B 2008. The identification of four characteristics of children's spirituality in Australian Catholic primary schools. International Journal of Children's Spirituality 13(2), May, 117-127.

Jenkinson, AJ 1946. What do boys and girls read? London: Methuen.

Kessler, R 1998. Nourishing students in secular schools. In Educational Leadership 56 (4), 49-52.

Kirby, D 2013. Fantasy and belief: Alternative religions, popular culture narratives and digital culture. Sheffield: Equinox Publishing Limited.

Kourie, C 2015. Weaving colourful threads: A tapestry of spirituality and mysticism. HTS (Teologiese Studies/Theological Studies) 71(1), Art. \#3023, 9 pages. http://dx.doi.org/10.4102/hts.v71i1.3023

Lewis, CS 1960. Miracles: A preliminary study. Glasgow: Collins Fount.

Lewis, CS 1962. They asked for a paper: Papers and addresses. London: Geoffrey Bles.

Lum, J 1982. Marginality and multiculturalism: Another look at bilingual / bicultural education. In LA Samovar \& EP Porter (eds.), Intercultural communication: A reader. Belmont, CA: Wadsworth.

McAvan, E 2012. The postmodern sacred: Popular culture spirituality in the science fiction, fantasy and urban genres. McFarland \& Company Inc. Publishers: London.

Millbank, J 2005. Fictioning things: Gift and narrative. In Religion \& Literature 37 (3) (autumn) 1-35. [Online]. Available: http:/www.jstor.org/ stable/40059993 [Accessed: 2 February 2014.

Miller-McLemore, BJ 2013. Theology, religious communities and practices. [Online]. Available: https://www.faithandleadership.com/qa/bonnie-jmiller-mclemore-theology-religious-communities-and-practice

Osmer, R \& Salazar-Newton, A. Practice of reading and the formation of the moral imagination. In Ecclesial Practices 1, 51-71

Partridge, C., 2004. The re-enchantment of the West, Volume 1, T \& T Clark International: London. 
Ray, R 2010. JK Rowling on the Oprah Winfrey Show in Edinburgh.

ABC: UStv review [Online]. Available: http://www.telegraph.co.uk/culture/ tvandradio/8041104/ http://www.telegraph.co.uk/

Ricoeur, P 1974. The conflict of interpretations: Essays in hermeneutics. In D Ihde (ed.). North-western University Press: Evanston.

Schofield, Clark L 2002. US adolescents, religious identity, the media, and the 'funky' side of religion. Journal of Communication December, $794-811$.

Sheldrake, P 2013 (2005). The new SCM dictionary of Christian Spirituality. SCM Press: London

Tacey, D 2003. Rising waters of the spirit. Studies in Spirituality 13, 11-30. http://dx.doi.org/10.2143/SIS.13.0.504586

Tolkien, JRR 1964. Tree and Leaf. Allen \& Unwin, London.

Tolkien, JRR 2008. Tolkien on Fairy-Stories. Expanded edition with commentary and notes. V Flieger \& DA Anderson DA (eds). Harper Collins Publishers, London.

Whitman, D \& Chetwynd, JN 1997. The youth crisis. In US News and World Report May 5, 122, 24.

Wilhelm, JD 2016. Recognising the power of pleasure: What engaged adolescent readers get from their free-choice reading, and how teachers can leverage this for all. Australian Journal of Language and Literacy Vol 39, No 1, 30-41.

Witmer, JM \& Sweeney, TJ 1992. A holistic model for wellness and prevention over a life span. In Journal of Counseling \& Development November/December, Volume 71, 140 - 148.

Zipes, J 2008. Why fantasy matters too much. In CLCWeb: Comparative Literature and Culture Vol 10, Issue 4, 2-12. 